\title{
Comparison of sweat rate during graded exercise and the local rate induced by pilocarpine
}

A.C. Vimieiro-Gomes, F.C. Magalhães, F.T. Amorim, C.A. Machado-Moreira, M.S. Rosa, N.R.V. Lima and L.O.C. Rodrigues

\author{
Laboratório de Fisiologia do Exercício, Escola de Educação Física, \\ Fisioterapia e Terapia Ocupacional, Universidade Federal de Minas Gerais, \\ Belo Horizonte, MG, Brasil
}

\section{Correspondence \\ L.O.C. Rodrigues \\ Av. Antônio Carlos, 6627 \\ 31310-250 Belo Horizonte, MG \\ Brasil \\ Fax: +55-31-3499-2325 \\ E-mail: lor@ufmg.br}

Research supported by $\mathrm{CNPq}$, FAPEMIG, CAPES, and Pro-Reitoria de Pós-Graduação da UFMG.

Received September 22, 2004 Accepted March 31, 2005

\begin{abstract}
Centrally stimulated sweat rate produced by graded exercise until exhaustion was compared to the local sweat rate induced by pilocarpine, often used as a sweating index for healthy individuals. Nine young male volunteers $(22 \pm 4$ years $)$ were studied in temperate environment in two situations: at rest and during progressive exercise with $25 \mathrm{~W}$ increases every 2 min until exhaustion, on a cycle ergometer. In both situations, sweating was induced on the right forearm with $5 \mathrm{ml} 0.5 \%$ pilocarpine hydrochloride applied by iontophoresis (1.5 mA, $5 \mathrm{~min}$ ), with left forearm used as control. Local sweat rate was measured for $15 \mathrm{~min}$ at rest. During exercise, whole-body sweat rate was calculated from the body weight variation. Local sweat rate was measured from the time when heart rate reached $150 \mathrm{bpm}$ until exhaustion and was collected using absorbent filter paper. Pharmacologically induced local sweat rate at rest $\left(0.4 \pm 0.2 \mathrm{mg} \mathrm{cm}^{-2} \mathrm{~min}^{-1}\right)$ and mean exercise-induced whole-body sweat rate $\left(0.4 \pm 0.1 \mathrm{mg} \mathrm{cm}^{-2}\right.$ $\left.\mathrm{min}^{-1}\right)$ were the same $(\mathrm{P}>0.05)$ but were about five times smaller than local exercise-induced sweat rate (control $=2.1 \pm 1.4$; pilocarpine $=$ $2.7 \pm 1.2 \mathrm{mg} \mathrm{cm}^{-2} \mathrm{~min}^{-1}$ ), indicating different sudorific mechanisms. Both exercise-induced whole-body sweat rate $(\mathrm{P}<0.05)$ and local sweat rate $(\mathrm{P}<0.05)$ on control forearm correlated positively with pilocarpine-induced local sweat rate at rest. Assuming that exerciseinduced sweating was a result of integrated physiological mechanisms, we suggest that local and whole-body sweat rate measured during graded exercise could be a better sweating index than pilocarpine.
\end{abstract}

\section{Introduction}

The ability of humans to dissipate heat during exercise and in hot environments depends mainly on the evaporation of sweat
Key words

- Sweat rate

- Graded exercise test

- Thermoregulation
- Pilocarpine 
The local sweat rate has been measured during pharmacological stimulation of the eccrine sweat glands with cholinergic agonists (methacholine, acetylcholine, pilocarpine) injected subcutaneously or administered by iontophoresis. The sweat rate induced by cholinergic agents is considered to reflect the maximal rate (2), and the sweat rate induced by pilocarpine at rest is regarded to be an objective index of sweat gland output and to reflect sweat production during continuous exercise (3-6).

Sweat production stimulated by the sympathetic system has been measured during prolonged exercise and/or exposure to different thermal environments to evaluate the acclimation status and to establish rehydration protocols according to water losses caused by sweating (7-9).

However, no studies are available assessing the sweat rate during graded exercise tests until exhaustion (GXT) despite the technical simplicity of its measurement. Physiological variables are determined in protocols habitually adopted for the measurement of aerobic power $\left(\mathrm{V}^{2} \mathrm{O}_{2 \operatorname{xax}}\right)$ : ventilatory volume, oxygen uptake, carbon dioxide extraction, respiratory exchange ratio, heart rate (HR), arterial pressure, lactate concentration, rate of perceived exertion (RPE), and body temperature. In addition, we are unaware of studies that compared sweat rate stimulated by graded exercise to sweat rate induced by pharmacological agents.

We hypothesized that high sympathetic nerve activity, which is observed during graded exercise intensity that elicits an HR above $150 \mathrm{bpm}$ (10), should be related to sweat production. Furthermore, we assumed that exercise sweating stimulation (central) would be different in nature than the pilocarpine stimulation (local) (6).

The purpose of the present study was to compare the centrally stimulated sweat rate (local and whole-body) produced by graded exercise until exhaustion with the local sweat rate induced by pilocarpine iontophoresis.

\section{Material and Methods}

The study was approved by the Research Ethics Committee of the Federal University of Minas Gerais (No. 238-02). All procedures were performed according to the norms of Resolution 196 of the National Health Council (1996) on scientific research involving humans, and written informed consent was obtained from each volunteer.

The experiments were carried out in a tropical region in the southern hemisphere between April and June 2003, a period comprising the end of autumn and beginning of winter, always from 7:30 to 10:00 am.

\section{Subjects}

Nine young male volunteers, considered to be healthy after medical examination, were submitted to anthropometric evaluation and determination of the following variables: body weight (Filizola ${ }^{\circledR}$ MF-100 scale, precision of $0.02 \mathrm{~kg}$, São Paulo, SP, Brazil), height, the sum of biceps, triceps, subscapular, pectoral, midaxillary, suprailiac, abdominal, midthigh, and medial calf skinfold thickness (Skinfold Caliper, Lange, Santa Cruz, CA, USA), and body surface area $\left(A_{D}\right)(11)$. The physical characteristics of the volunteers were: age, $22 \pm 4$ years; body weight, $69.56 \pm 7.60 \mathrm{~kg}$; height, $176.5 \pm 6.0 \mathrm{~cm} ; \mathrm{A}_{\mathrm{D}}$, $1.8 \pm 0.1 \mathrm{~m}^{2}$; sum of skinfolds, $68 \pm 23 \mathrm{~mm}$.

The volunteers were instructed to refrain from tobacco, caffeine, alcoholic beverages and drugs, to abstain from physical activities $24 \mathrm{~h}$ before the experiments and to sleep at least $8 \mathrm{~h}$ during the night prior to the experiments. The subjects were asked to ingest 500 $\mathrm{ml}$ of water $2 \mathrm{~h}$ before each session to guarantee their euhydrated status. Upon arrival at the laboratory, urine specific gravity (JSCP-Uridens, São Paulo, SP, Brazil) was measured and was always lower than 1030 in both experimental situations. During the experiments, the volunteers wore shorts, socks and sports shoes. 


\section{Procedures}

The study was conducted in two situations: a) measurement of local sweat rate at rest (only the pilocarpine iontophoresis test as the "gold standard"; REST), and b) measurement of local (control and pilocarpine) and whole-body sweat rate during progressive exercise until exhaustion on a cycle ergometer (GXT). The order of the experimental situations was randomized and crossed.

At REST and during GXT, sweating was induced locally in the right forearm with 5 $\mathrm{ml} 0.5 \%(50 \mathrm{mg} / \mathrm{ml})$ pilocarpine hydrochloride (Galena Química e Farmacêutica, Campinas, SP, Brazil) applied by iontophoresis (1.5 mA, $\left.60 \mu \mathrm{A} \mathrm{cm}^{-2}, 5 \mathrm{~min}\right)$ as described by Gibson and Cooke (12) and Buono and Sjoholm (3). In the resting condition, after induction with pilocarpine, the volunteers remained in the sitting position for $15 \mathrm{~min}$ for the collection of sweat from the right forearm.

Immediately before GXT, induction of sweating with pilocarpine was repeated in the right forearm, with the left forearm being used as control. Symmetry between the right and left forearm was assumed. Initial body weight was measured immediately after induction. Next, the volunteers pedaled on a mechanically braked cycle ergometer (Monark, 824E, Varberg, Sweden) according to the ACSM (13) protocol used for the assessment of aerobic power. The exercise was progressive, starting with a 50-W load, followed by $25-\mathrm{W}$ increases every $2 \mathrm{~min}$ until the individual reached one of the exhaustion criteria, i.e., the volunteer asked to stop the exercise (subjective exhaustion), stabilization of $\mathrm{HR}$ or $\dot{\mathrm{VO}}_{2}$ occurred despite an increase in the ergometer workload, and a respiratory exchange ratio higher than 1 . At this point, total exercise time was measured. After exhaustion, the volunteers continued pedaling for $2 \mathrm{~min}$ at a $50-\mathrm{W}$ load, and then remained sitting for $3 \mathrm{~min}$. Final body weight was then measured and whole-body sweat rate $\left(\mathrm{mg} \mathrm{cm}^{-2} \mathrm{~min}^{-1}\right)$ was calculated by dividing body weight variation by time between measurements (min) and by $A_{D}\left(\mathrm{~cm}^{2}\right)$, uncorrected for respiratory water loss and metabolic weight loss.

The following variables were measured during GXT: ventilation (1 $\left.\mathrm{min}^{-1}\right)$, oxygen uptake $\left(\dot{\mathrm{V}}_{2}, 1 \mathrm{~min}^{-1}\right)$, carbon dioxide extraction $\left(\dot{\mathrm{VCO}}_{2}, 1 \mathrm{~min}^{-1}\right)$ and respiratory exchange ratio, which were determined with an open-circuit spirometer (Medigraphics VO-2000, Ann Arbor, MI, USA), and HR (Polar Vantage NV, Kempele, Finland). RPE was determined every 2 min using the Borg scale. In addition, rectal temperature $\left(\mathrm{T}_{\mathrm{re}}\right)$ was measured with a disposable rectal probe (YSI, 4400 series - 4491-E, Yellow Springs, $\mathrm{OH}$, USA) inserted $10 \mathrm{~cm}$ beyond the anal sphincter. Mean skin temperature $\left(\overline{\mathrm{T}}_{\mathrm{sk}}\right)$ was determined with skin thermosensors (YSI, 400 series) positioned on the chest, arm, thigh and leg, and calculated by the following equation: $\overline{\mathrm{T}}_{\mathrm{sk}}=0.3($ chest $+\operatorname{arm})+0.2$ (thigh + leg) (14). The mean body temperature $\left(\overline{\mathrm{T}}_{\mathrm{b}}\right)$ was calculated using the $\overline{\mathrm{T}}_{\mathrm{b}}=0.67$ $\left(\mathrm{T}_{\mathrm{re}}\right)+0.33\left(\overline{\mathrm{T}}_{\mathrm{sk}}\right)$ equation.

During GXT, pilocarpine-stimulated local sweat production on the right forearm was measured from the moment when HR reached $150 \mathrm{bpm}$ until exhaustion and sweat production on the left forearm was used as control. This HR was chosen to permit the observation of sweating during a phase of the exercise when the sympathetic nervous system is activated (10). Local sweat production during GXT and at REST was determined using a $16-\mathrm{cm}^{2}$ piece of absorbent filter paper (J Prolab, S.J. dos Pinhais, PR, Brazil) positioned in the medial region close to the elbow joint of the right and left forearms. To prevent sweat evaporation, the absorbent filter papers were covered with a 64$\mathrm{cm}^{2}$ piece of plastic fixed to the skin with impermeable adhesive tape. The sweat rate was the difference in weight of the absorbent filter paper before and after sweat collection 
(Mettler Toledo AB 204 analytical scale, precision of $0.1 \mathrm{mg}$, Columbus, OH, USA) divided by the area of the absorbent filter paper and time of sweat collection $\left(\mathrm{mg} \mathrm{cm}^{-2}\right.$ $\left.\min ^{-1}\right)$.

The procedures were performed in a room $\left(40 \mathrm{~m}^{3}\right)$ with the following environmental thermal conditions: REST $=21 \pm 0.4^{\circ} \mathrm{C}$ and relative humidity $=65 \pm 4 \%$; GXT $=21 \pm$ $0.5^{\circ} \mathrm{C}$ and relative humidity $=67 \pm 5 \%$, kept constant with a commercial air conditioner

Table 1. Variables measured during the graded exercise test.

\section{Variable}

\begin{tabular}{|c|c|}
\hline$W_{\max }(\mathrm{W})$ & $292 \pm 45$ \\
\hline RPE & $19 \pm 1$ \\
\hline Total exercise time ( $\mathrm{min}$ ) & $21.6 \pm 3.3$ \\
\hline $\mathrm{HR}_{\max }(\mathrm{bpm})$ & $190 \pm 7$ \\
\hline$\dot{\mathrm{V}}_{2 \max }\left(\mathrm{ml} \mathrm{kg} \mathrm{kg}^{-1} \mathrm{~min}^{-1}\right)$ & $56.9 \pm 11.8$ \\
\hline$\dot{V} E_{\max }\left(I \mathrm{~min}^{-1}\right)$ & $94.3 \pm 10.9$ \\
\hline $\mathrm{V} \mathrm{CO}_{2 \max }\left(\mathrm{I} \mathrm{min}^{-1}\right)$ & $4.1 \pm 0.7$ \\
\hline $\mathrm{R}_{\max }$ & $1.1 \pm 0.1$ \\
\hline
\end{tabular}

Data are reported as means \pm SD for 9 male volunteers. $W_{\max }=$ maximal power; $\mathrm{RPE}=$ final rate of perceived exertion; $\mathrm{HR}_{\max }=$ maximal heart rate; $\dot{\mathrm{V}}_{2 \max }=$ maximal oxygen uptake; $\dot{\mathrm{V}} \mathrm{E}_{\max }=$ maximal ventilation; $\dot{\mathrm{V}} \mathrm{CO}_{2 \max }=$ maximal carbon dioxide extraction; $R_{\max }=$ maximal respiratory exchange ratio. The values reported for $\dot{\mathrm{V}}_{2 \max }$, $\dot{\mathrm{V}} \mathrm{E}_{\max }, \dot{\mathrm{V}} \mathrm{CO}_{2 \max }$, and $\mathrm{R}_{\max }$ are the mean of the three highest values obtained during the last stage of the GXT. GXT = graded exercise tests until exhaustion.

Table 2. Variation of body temperatures at rest and during graded exercise tests until exhaustion.

\begin{tabular}{lcc}
\hline Temperature $\left({ }^{\circ} \mathrm{C}\right)$ & REST & GXT \\
\hline$\Delta \overline{\mathrm{T}}_{\text {re }}$ & $0.1 \pm 0.1$ & $0.4 \pm 0.2^{*}$ \\
$\Delta \overline{\mathrm{T}}_{\mathrm{sk}}$ & $0.1 \pm 0.1$ & $2.6 \pm 0.6^{*}$ \\
$\Delta \overline{\mathrm{T}}_{\mathrm{b}}$ & $0.1 \pm 0.1$ & $1.1 \pm 0.3^{*}$
\end{tabular}

Variables are reported as mean \pm SD for 9 male volunteers. $\Delta \overline{\mathrm{T}}_{\mathrm{re}}=$ rectal temperature variation; $\Delta \overline{\mathrm{T}}_{\text {sk }}=$ skin temperature variation; $\Delta \overline{\mathrm{T}}_{\mathrm{b}}=$ body temperature variation. GXT = graded exercise tests until exhaustion. *Body temperature variations were greater at GXT than at REST $(P<0.05$, Student Newman-Keuls test).
(Consul AirMaster 7500, São Paulo, SP, Brazil).

\section{Statistical analysis}

One-way ANOVA and the post hoc Student-Newman-Keuls test were used to compare mean local sweat rate and mean body temperatures at rest and during GXT. Pearson's correlation was calculated between the pilocarpine-induced sweat rate for the right forearm at rest (independent variable) and whole-body sweat rate and local sweat rate for the left forearm (control) during GXT (dependent variables). Data are reported as means $\pm \mathrm{SD}$ and the level of significance was set at $5 \%$.

\section{Results}

Table 1 shows the variables measured during GXT. RPE was higher than 18, HR reached $190 \mathrm{bpm}$ and the respiratory exchange ratio was higher than 1 , showing that exercise was performed until exhaustion. In addition, the subjects reached a maximum power of $292 \mathrm{~W}$ corresponding to a $\dot{\mathrm{V}} \mathrm{O}_{2 \max }$ of $56.9 \mathrm{ml} \mathrm{kg}^{-1} \mathrm{~min}^{-1}$.

Table 2 shows the variations in body temperature during REST and GXT. The variations in rectal temperature, mean skin temperature and mean body temperature were greater during GXT than at REST $(\mathrm{P}<0.05)$.

Figure 1 shows the whole-body sweat rate obtained during GXT, the pilocarpineinduced local sweat rate at rest and the local sweat rate on the pilocarpine-induced and control forearms during GXT. The local sweat rate of both forearms was about five times higher in the GXT situation than the pilocarpine-induced local sweat rate at rest $(\mathrm{P}<0.05)$. However, during GXT, the local sweat rate on the pilocarpine-induced forearm did not differ from the sweat rate on the control forearm $(\mathrm{P}>0.05)$.

Figure 2 shows that a positive and significant correlation was observed between 
the control local sweat rate (left forearm) and whole-body sweat rate during GXT, with a correlation coefficient $(\mathrm{r})$ of $0.92, \mathrm{P}=$ 0.001

As shown in Figure 3, positive and significant correlations were observed between A) the pilocarpine-induced local sweat rate at rest and whole-body sweat rate $(r=0.70$, $\mathrm{P}=0.03)$, and $\mathrm{B})$ the pilocarpine-induced local sweat rate at rest (right forearm) and the control local sweat rate (left forearm) during GXT ( $\mathrm{r}=0.73, \mathrm{P}=0.02)$.

\section{Discussion}

The most important result of the present study was that the exercise stimuli induced a higher local sweat rate than pilocarpine stimulation (Figure 1). In addition, there was a positive and significant correlation between the pilocarpine-induced local sweat rate at rest and whole-body and local sweat rate during GXT (Figure 3), indicating that both variables could be used as an index of sweat gland output. However, GXT is a more widely used procedure for the measurement of aerobic power, for clinical diagnosis and for exercise prescription than pilocarpine iontophoresis, a method practically restricted to the diagnosis of cystic fibrosis and to scientific studies.

In the present study, the mean wholebody sweat rate during GXT was found to be similar to the pilocarpine-induced local sweat rate at rest. On the other hand, the higher local sweat rate observed during exercise (Figure 1) suggests that the mechanisms underlying the two sweat rates are different: the neural central stimuli of GXT seem to be greater than the local pilocarpine stimulus directly applied to the eccrine sweat glands. Thus, exercise-induced sweating is triggered by an integrated central-peripheral physiological mechanism. Moreover, the similar local sweat rate observed in pilocarpineinduced and control forearms during GXT indicates that pilocarpine did not act as an additional stimulus besides the central stimuli from exercise on the eccrine sweat glands.

Pilocarpine is a cholinergic agonist able to directly stimulate the eccrine sweat gland

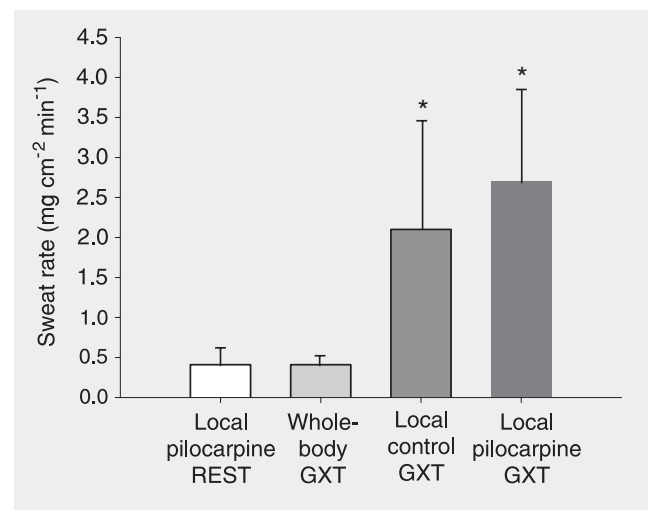

Figure 1. Whole-body and local sweat rates at rest (REST) and during graded exercise tests until exhaustion (GXT). Data are reported as mean \pm SD for 9 male volunteers. Local pilocarpine REST = sweat rate on the right forearm after $15 \mathrm{~min}$ of pilocarpine iontophoresis. Whole-body GXT = whole-body sweat rate during GXT. Local control GXT = sweat rate on the left forearm produced by exercise. Local pilocarpine GXT = sweat rate on the right forearm induced by exercise in combination with pilocarpine. *Local control GXT and local pilocarpine GXT greater than local pilocarpine REST $(P<0.05$, Student Newman-Keuls test).

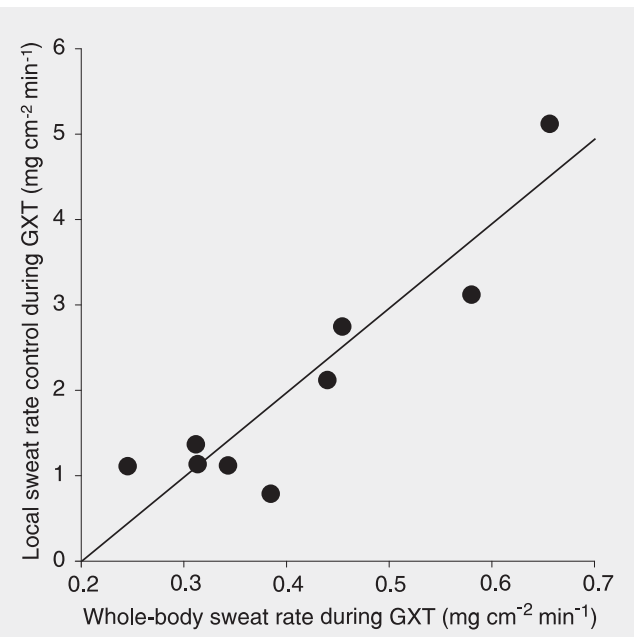

Figure 2. Correlation between whole-body sweat rate and local sweat rate on the left forearm (control) during the graded exercise test until exhaustion (GXT). The Pearson correlation test was used to obtain $r=0.92$ and $\mathrm{P}=0.001$. 
by activating acetylcholine receptors, without the need for stimulation of periglandular nerve endings. GXT is a physiological situation corresponding to heat-producing physical activities, which depends on the secretion of sweat by the eccrine sweat glands for the maintenance of homeostasis. Thus, the measurement of sweat gland output based on GXT seems to be more adequate to express real physiological adjustments than measurement by pilocarpine induction.

Sweat production stimulated by the sympathetic autonomic nervous system (cholinergic) is known to depend on thermal and non-thermal mechanisms. Hypothalamic stimuli increase sweat production, which is proportional to the internal body temperature (as a result of body metabolism) and skin temperature (as a result of thermal environmental stress) $(15,16)$. Non-thermal stimuli such as certain emotional states and mental activities, the level of mental alertness and exercise-related factors (activation of central drive and muscle mechano- and metaboreceptors) also trigger sudorific responses immediately after stimulation, and these responses are dissociated from the variation in body temperature (17-19). It is possible that the sweat production observed in the present study during GXT was the result of neural stimuli originating from thermal and non-thermal mechanisms and that the pilocarpine-induced sweat rate was only a consequence of local stimulation of the eccrine sweat glands.

Furthermore, exercise is known to induce higher concentrations of noradrenaline, adrenaline and vasoactive peptides (10) which might represent co-factors in the sudorific response (1), variations in plasma osmolality (20), greater local blood flow (21), and increased temperature in the periglandular region (16). Thus, it could be hypothesized that these physiological factors may play a role in the response of the eccrine sweat gland during exercise, contributing to the differences in sweating between the two situations (REST and GXT).

We observed wider intra-subject variability in the sweat rate induced by the pharmacological agent at rest than in the sweat rate induced by exercise (Figure 3). This finding suggests a broader range of glandular sensitivity to pilocarpine iontophoresis than to the central stimuli, related to biological variations (gland size, skin temperature, acclimation status, and training effect).

Another important finding was the positive and significant correlation observed between whole-body sweat rate and the local sweat rate on the left forearm (control), both produced by GXT (Figure 2), indicating that the forearm responded to exercise with a proportional sweat production. This finding
Figure 3. $A$, Correlation between the local sweat rate on the right forearm induced by pilocarpine at rest (REST) and whole-body sweat rate during the graded exercise test until exhaustion (GXT; r $=0.70, P=0.03$, Pearson correlation test). $B$, Correlation between the local sweat rate on the right forearm induced by pilocarpine at rest and the local sweat rate on the left forearm (control) during GXT ( $r=0.73, P$ $=0.02$, Pearson correlation test).

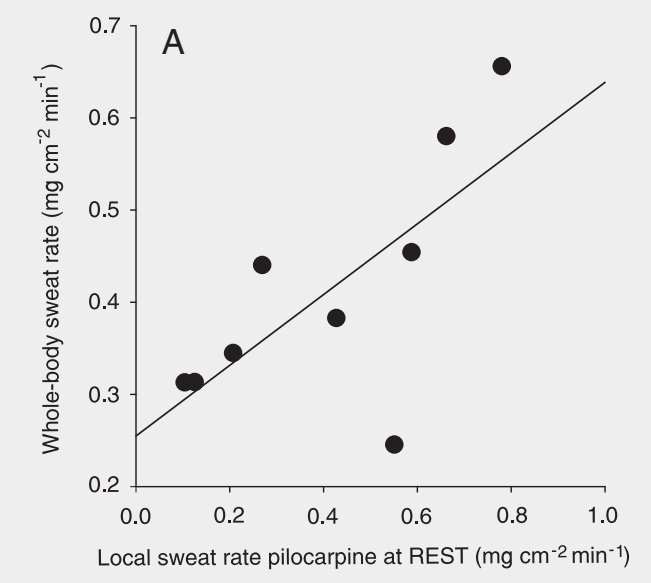


corroborates the known principle of universal sweating in response to central thermal stimuli (17) and may indicate that the forearm is an area effectively participating in sweat production during exercise, as reported in the literature (22-24). Thus, this result shows that the measurement of forearm sweat rate reflects the whole-body sweat rate produced during GXT.
In conclusion, the integrated central-peripheral physiological mechanism during graded exercise elicited a greater sweating response than local stimulation with pilocarpine. Thus, we suggest that local and whole-body sweat rate measured during graded exercise is more adequate to express physiological sudorific adjustments, being a better sweating index than pilocarpine.

\section{References}

1. Sato K, Kang WH, Saga K \& Sato KT (1989). Biology of sweat glands and their disorders. I. Normal sweat gland function. Journal of the American Academy of Dermatology, 20: 537-563.

2. Sato K \& Sato F (1990). Methods for studying eccrine sweat gland function in vivo and in vitro. Methods in Enzymology, 192: 583-599.

3. Buono MJ \& Sjoholm NT (1988). Effect of physical training on peripheral sweat production. Journal of Applied Physiology, 65: 811-814.

4. Davis SL, Wilson TE, Vener JM, Crandall CG, Petajan JH \& White AT (2005). Pilocarpine-induced sweat gland function in individuals with multiple sclerosis. Journal of Applied Physiology (in press).

5. Buono MJ, White C \& Connolly KP (1991). Pilocarpine-induced sweat rate at rest versus whole body sweat rate during exercise. Journal of Applied Sport Science Research, 5: 82-86.

6. Hjortskov N, Jepsen LT, Nielsen B, Juul A \& Skakkebaek NE (1995). Pilocarpine iontophoresis test: an index of physiological sweat secretion? Clinical Physiology, 15: 409-414.

7. Nielsen B, Strange S, Christensen NJ, Warberg J \& Saltin B (1997). Acute and adaptive responses in humans to exercise in a warm, humid environment. Pflügers Archiv. European Journal of Physiology, 434: 49-56.

8. Armstrong LE, Maresh CM, Gabaree CV, Hoffman JR, Kavouras SA, Kenefick RW, Castellani JW \& Ahlquist LE (1997). Thermal and circulatory responses during exercise: effects of hypohydration, dehydration, and water intake. Journal of Applied Physiology, 82: 2028-2035.

9. Vimieiro-Gomes AC \& Rodrigues LOC (2001). Avaliação do estado de hidratação dos atletas, estresse térmico do ambiente e custo calórico do exercício durante sessões de treinamento em voleibol de alto nível. Revista Paulista de Educação Física, 15: 201-211.

10. Rowell LB \& O'Leary DS (1990). Reflex control of the circulation during exercise: chemoreflexes and mechanoreflexes. Journal of Applied Physiology, 69: 407-418.

11. Dubois D \& Dubois EF (1916). A formula to estimate the approximate surface area if height and weight be known. Archives of Internal Medicine, 17: 831-836.

12. Gibson LE \& Cooke RE (1959). A test for concentration of electrolytes in sweat in cystic fibrosis of the pancreas utilizing pilocarpine by iontophoresis. Pediatrics, 23: 545-549.

13. American College of Sports Medicine (2000). Guidelines for Exercise Testing and Prescription. 6th edn. Lippincott Williams \& Wilkins, Philadelphia, PA, USA.

14. Ramanathan NL (1964). A new weighting system for mean surface temperature of the human body. Journal of Applied Physiology, 19: 531-533.

15. Nadel ER, Bullard RW \& Stolwijk JAJ (1971). Importance of skin temperature in the regulation of sweating. Journal of Applied Physiology, 31: 80-87.

16. Nadel ER, Mitchell JW, Saltin B \& Stolwijk JAJ (1971). Peripheral modifications to the central drive for sweating. Journal of Applied Physiology, 31: 828-833.

17. Kuno Y (1956). Human Perspiration. Charles C. Thomas Publisher, Springfield, IL, USA.

18. Yamazaki F, Sone R \& Ikegami H (1994). Responses of sweating and body temperature to sinusoidal exercise. Journal of Applied Physiology, 76: 2541-2545.

19. Shibasaki M, Kondo N \& Crandall CG (2003). Non-thermoregulatory modulation of sweating in humans. Exercise and Sport Sciences Reviews, 31: 34-39.

20. Fortney SM, Wenger CB, Bove JR \& Nadel ER (1984). Effect of hyperosmolality on control of blood flow and sweating. Journal of Applied Physiology, 56: 1688-1695.

21. Sugenoya J, Iwase S, Mano T, Sugiyama Y, Ogawa T, Nishiyama T, Nishimura N \& Kimura T (1998). Vasodilator component in sympathetic nerve activity destined for the skin of the dorsal foot of mildly heated humans. Journal of Physiology, 507: 603-610.

22. Cotter JD, Patterson MJ \& Taylor NA (1995). The topography of eccrine sweating in humans during exercise. European Journal of Applied Physiology and Occupational Physiology, 71: 549-554.

23. Kondo N, Takano S, Aoki K, Shibasaki M, Tominaga H \& Inoue $Y$ (1998). Regional differences in the effect of exercise intensity on thermoregulatory sweating and cutaneous vasodilation. Acta Physiologica Scandinavica, 164: 71-79.

24. Buono MJ (2000). Limb vs trunk sweat gland recruitment patterns during exercise in humans. Journal of Thermal Biology, 25: 263266. 